\title{
Development and psychometric evaluation of a new team effectiveness scale for all types of community adult mental health teams: A mixed methods approach
}

\begin{abstract}
Defining 'effectiveness' in the context of community mental health teams (CMHTs) has become increasingly difficult under the current pattern of provision required in National Health Service (NHS) mental health services in England. The aim of this study was to establish the characteristics of multi-professional team working (MPTW) effectiveness in adult CMHTs in order to develop a new measure of CMHT effectiveness. The study was conducted between May and November 2010 and comprised two stages. Stage 1 used a formative evaluative approach based on the Productivity Measurement and Enhancement System to develop the scale with multiple stakeholder groups over a series of qualitative workshops held in various locations across England. Stage 2 analysed responses from a crosssectional survey of 1500 members in 135 CMHTs from 11 Mental Health Trusts in England to determine the scale's psychometric properties. Based on an analysis of its structural validity and reliability, the resultant 20 -item scale demonstrated good psychometric properties and captured one overall latent factor of CMHT effectiveness comprising seven dimensions: improved service user well-being, creative problem solving, continuous care, inter-team working, respect between professionals, engagement with carers, and therapeutic relationships with service users. The scale will be of significant value to CMHTs and healthcare commissioners both nationally and internationally for monitoring, evaluating and improving team functioning in practice.
\end{abstract}

Key words: Community mental health care, teamwork, team effectiveness, Productivity Measurement and Enhancement System, scale development. 


\section{What is known about this topic?}

- Multi-professional team working (MPTW) in community mental healthcare is increasingly prevalent but highly challenging.

- Team types and functions of CMHTs in England have changed, rendering existing measures of CMHT effectiveness invalid.

- Definition and measurement of CMHT effectiveness needs to be representative of the unique emerging context and multiple stakeholder groups.

\section{What this paper adds:}

- Stakeholders agreed that CMHT effectiveness comprised seven dimensions, which are captured on a 20 -item scale.

- These dimensions are: improved service user well-being, creative problem solving, continuous care, inter-team working, respect between professionals, engagement with carers, and therapeutic relationships with service users.

- The measure has proved to be psychometrically sound and can be used to evaluate and improve CMHT functioning nationally and internationally, and across a range of settings. 


\section{Introduction}

Multi-professional team working (MPTW) in healthcare is characterised by close interdependent collaboration of health care professionals from different occupational groups to deliver an integrated care package (Jansen \& Glasby, 2008). In a continuous quest to improve both the quality and integration of care (El Ansari, 2011), along with increased requirements for interdependence, skill specialisation and medical knowledge, the use of multi-professional teams in health services continues to grow (Nembhard \& Edmondson, 2006). MPTW has a long history in English mental health care and has become even more pronounced in recent years, following publication of the UK Government's National Service Framework for Mental Health (NSF-MH) in 1999 and the Mental Health Policy Implementation Guide (MH-PIG) in 2001. Together these reports established that the bulk of National Health Service (NHS) mental health service provision takes the form of a community based service offered by a family of multi-professional teams. More recent changes in service configuration have led to some amalgamations and changes of team function. The range of community mental health team (CMHT) types and their core functions are summarised in Table 1.

\section{Insert table 1 here}

Nevertheless, regardless of team type and function, CMHTs face several distinct challenges in relation to MPTW. These include the generally complex environment in which they work (e.g., diverse and challenging service user needs, increased need for service user and carer involvement, relatively high caseloads and multiple demands from external constituents); the competing pressures and priorities they face (e.g., chronic lack of resources, competing interests around prioritising needs; Onyett, 2003); as well as the management of 
team processes which are typically more difficult in diverse multi-professional CMHTs (e.g., Brown et al., 2000; Dickinson et al., 2007; Richards \& Rees, 1998; Rees et al., 2004). Collectively, these characteristics mean that 'effectiveness' in the context of community mental healthcare becomes multifaceted, difficult to define and subject to the diverse, and often competing requirements of the stakeholders involved (El Ansari, 2003). Previous measures of CMHT effectiveness include the Community Mental Health Team Effectiveness questionnaire (CMHTEQ; Richards \& Rees, 1998; Rees et al., 2001), which covers 27 effectiveness criteria capturing three dimensions; meeting external requirements, internal team processes, and evidence and feedback. While the CMHTEQ has provided service managers with a useful means of monitoring team performance, its development focused solely on generic CMHTs, and it is therefore less reflective of the current service configuration in the NHS. Thus, there is a pressing need for a more comprehensive and psychometrically sound measure of CMHT effectiveness that is representative of the unique context, captures various types and functions of all teams, and is sensitive to the views of multiple stakeholders (Lester \& Glasby, 2012).

In this paper, we describe the development and psychometric testing of a questionnaire scale that holistically captures the effectiveness of MPTW in CMHTs from the perspectives of multiple stakeholders (i.e. service providers, users and carers). This scale was developed using principles from the Productivity Measurement and Enhancement System (ProMES) methodology. ProMES is based upon the development of effectiveness criteria initially established in group discussions that involve all stakeholders with an interest in team functioning. Variables derived from these criteria are then psychologically scaled to form a common effectiveness measure that can subsequently be used to compare, monitor and improve performance, and provide feedback. A detailed review of the theoretical background, mechanics and research evidence related to ProMES are presented elsewhere (see Pritchard, 
1990; Pritchard et al., 2008). As a generic approach to team working, ProMES has enjoyed wide application as it enables the development of context specific measures that capture multiple stakeholder perspectives. Thus, not only is it an approach capable of providing insights into the MPTW of CMHTs, but in the course of doing so, it generates a new team effectiveness scale.

Overall, the current study had two specific objectives. The first objective was to apply the ProMES methodology to the development of a team effectiveness scale in the context of community mental health care. The second objective was to assess the psychometric properties of the new CMHT effectiveness scale in terms of its structural validity and reliability.

\section{Methods}

This mixed-method study comprised two stages, detailed in turn below. Qualitative and quantitative data for the study were collected between May and November 2010, and both stages of the study (see below) were approved by the NHS Black Country Research Ethics Committee (Ref. 09/H1202/118).

\section{Stage 1: Qualitative Scale Development}

Design. Stage 1 (scale development) was a three-phase qualitative study based on a formative evaluative approach that employed an iterative process with various stakeholder constituencies in order to develop a quantitative measure of CMHT effectiveness.

Sample. Trusts volunteered for inclusion in the study based on information submitted to them on behalf of the research team by the Mental Health Research Network (MHRN), part of England's National Institute for Health Research (NIHR). Fourteen English mental health service provider Trusts expressed interest in taking part, of which 12 agreed to participate. One subsequently withdrew its agreement before the study commenced, leaving 
11 Trusts participating. Trusts were selected to represent a good cross-section nationally by region, urban/rural setting, population demographics and performance. They covered the southern part of North West England, East of England (predominantly rural but includes major urban centres), East and West Midlands (includes three major cities), South West England (includes major urban centres), South of England (south of London, includes midsized urban centres), and London. Participating Trusts provided the research team with contacts in their Research and Development (R\&D) departments to negotiate access. Based on strategic sampling to ensure the sufficient representation of all stakeholder groups, individuals $(\mathrm{N}=157)$ from the 11 Mental Health Trusts participated in 10 workshops to develop an MPTW effectiveness measure in CMHTs. The sample comprised service users and carers, and providers from all major professional groups (social work, psychiatry, psychology, occupational therapy and nursing, administrators and unqualified support workers) representing all types of CMHTs outlined in table 1.

Procedure. The 10 workshops were conducted as three phases. Prior to each workshop phase, all participants were required to read an information sheet and sign a consent form in order to provide their informed consent to take part. Table 2 provides the details of the workshops' membership as well as tasks that were undertaken in each. Following ProMES methodology, Phase 1 workshops established what the outcomes of effective CMHTs are from consensus drawn out of two large workshops convened and facilitated to explore such outcomes. Phase 2 workshops comprised structured discussions that elicited participants' ideas about each of the indicators of effectiveness derived from Phase 1, in terms of how participants would know whether or not the outcomes were achieved, and how these outcomes could be measured using questionnaire items. In Phase 3, participants examined the suitability and wording of the emerging questionnaire items to 
ensure that questions were representative of their respective theme and appropriately understood. Items were then amended accordingly by the research team.

Insert table 2 here

Analysis. Employing grounded theory as an inductive paradigm (Glaser \& Strauss, 1967), data analysis and extraction of major themes or 'objectives' from the Phase 1 workshops were undertaken via thematic analysis (Braun \& Clarke, 2006). Two members of the research team immersed themselves in the qualitative data and discussed the content at length. Then, initial codes were generated by highlighting appropriate text, before searching for overall themes in the data. At this stage, seven major themes emerged and were given names. The research team collectively reviewed these themes, revisiting the data to check that nothing was missed.

Subsequently, three validity checks were undertaken. Firstly, following each Phase 1 workshop participants received a workshop summary report structured around the seven derived themes. Participants were invited to comment on and correct anything felt to be missing or not sufficiently captured. The research team received positive responses from all stakeholder groups, and subsequent amendments to the themes were not deemed necessary. Secondly, members of the research team presented the seven themes at a service user and carer event held shortly afterwards, and participants collectively expressed their satisfaction with the themes. Finally, at the beginning of each Phase 2 workshop, participants were informed of the Phase 1 themes and were invited to comment on their face validity and completeness. No major concerns were raised, leaving the research team confident that the Phase 1 themes accurately represented all participating stakeholders' perspectives. 
For phases 2 and 3, data analysis was largely conducted by the participants during the workshops. The Phase 2 workshops generated 10 to 15 potential questionnaire items for each of the themes identified in Phase 1. This resulted in a pool of 80 items, which was initially reduced by the research team by removing unclear, overlapping and redundant items. Two large full-day externally facilitated Phase 3 workshops were then conducted with service providers, users and carers to enable further refining and cognitive testing of the items, with a view to identifying the most suitable items for inclusion in the new scale.

The resultant CMHT effectiveness scale comprised 20 items capturing the seven themes. Twelve of the items were positively worded and eight were negatively worded, and team members were asked to respond on a five-point Likert scale $(1=$ strongly disagree; $5=$ strongly agree). Self-reported team member responses were then aggregated to the team level of analysis to capture overall CMHT effectiveness.

\section{Stage 2: Quantitative Scale Evaluation}

Design. Stage 2 (scale evaluation) incorporated the newly derived CMHT effectiveness scale in a quantitative questionnaire to team members of CMHTs in order to assess its psychometric properties.

Sample. Stage 2 comprised a questionnaire of team members in the 11 Trusts recruited in Stage 1. These Trusts were representative of all mental health trusts nationally regarding the extent of their self-reported team working. According to the 2009 NHS National Staff Survey (Care Quality Commission, 2010), which was the closest in time to participation in the current study, $41 \%$ of staff in the participating Trusts reported working in well-structured teams; the same percentage of staff in Trusts not participating in the study. Teams were recruited with the help of local MHRN Clinical Studies Officers (CSOs). All teams within each Trust were based in a single locality (usually coterminous with a primary 
care Trust and/or local authority). We aimed to survey 10-15 teams per Trust, so that a crosssection of the different types of CMHT from each Trust could be included.

Procedure. Teams were invited to participate by their respective CSO directly. CSOs forwarded details of CMHT members to the research team, who then invited them by email to complete an online questionnaire. Before completing the questionnaire, team members were asked to read a cover sheet which provided information about the study and participation, and clarified that by completing and returning the questionnaire, respondents were providing their implicit informed consent to participate. In a few cases where information technology provision was not considered appropriate, CMHT members were invited to complete a paperbased questionnaire by post. Staff who were members of multiple teams could only respond to the survey once. In order to motivate Trusts' inclusion in the study, the research team offered to provide each participating team with a benchmarked feedback report detailing how their team compared with the wider sample on each dimension of the new CMHT effectiveness scale, along with more general team effectiveness dimensions applicable to all types of healthcare teams captured by the Aston Team Performance Inventory (ATPI; West et al., 2005). The ATPI is a comprehensive diagnostic tool of team performance in healthcare comprising 100 items that capture distinct aspects of team inputs (e.g., task design, skills), team processes (e.g., leadership, conflict), and team outputs (e.g., team member satisfaction, innovation). The team-specific feedback reports provided by the research team suggested areas of strength and possible improvement for the participating teams. However, data from the ATPI items was not incorporated into the quantitative analysis presented in this paper.

Analysis. The reliability of the new scale was assessed in terms of Cronbach's alpha, intraclass correlations $[\mathrm{ICC}(2)]$ for inter-rater reliability, and inter-rater agreement mean $\left[r_{W G(J)}\right]$ at the team level. Regarding structural validity, following standard practice for scale development (Hinkin, 1995), the sample $(\mathrm{N}=1500)$ was initially split at random into two 
halves. The first half was employed for exploratory factor analysis (EFA); the second half for confirmatory factor analysis (CFA) and reliability testing. As a first step, EFA on the 20 items was conducted using IBM SPSS Statistics for Windows, Version 19 (2010), and undertaken using principal axis factoring and a direct oblimin (oblique) rotation - considered the most appropriate methods for organisational data where factors could be correlated (Conway \& Huffcutt, 2003). The EFA suggested four competing models. Then, CFA was conducted in Mplus (version 6) to test the fit indices for each of the four competing models. Generally, the standardised root mean residual (SRMR) should ideally be $<0.1$ for adequate fit or $<.05$ for good fit, the comparative fit index $(\mathrm{CFI})>0.90$, the Tucker-Lewis index (TLI) $>0.90$, and the root mean square error of approximation (RMSEA) $<0.08(\mathrm{Hu} \&$ Bentler, 1998).

\section{Results}

\section{Stage 1: Qualitative data resulting in provisional measures of CMHT effectiveness}

Phase 1. Seven major themes inductively emerged from the analysis of Phase 1 workshop data (see table 3). These themes addressed a range of inter-related aspects relating to the focus, relationships, engagement, creativity and attitudes of CMHTs. Themes highlighted the need for an emphasis on service user well-being and recovery; the importance of therapeutic relationships between staff and service users; the benefits attached to the provision of continuous care; the necessity of effective inter-team working; the prerequisite of engagement with carers; the value of creative problem solving in terms of developing innovative solutions to service user problems; and, respect between the different disciplines represented in CMHTs. Table 3 shows the seven major themes along with example statements that emerged from the two Phase 1 workshops.

Insert table 3 here 
Phase 2. This phase elicited participants' views of how an observer might detect the presence or absence of the themes identified in Phase 1. There were separate workshops for users and carers in this phase because, during Phase 1, these two stakeholder groups exhibited different and often conflicting views about MPTW in mental health care, which at times hampered an open exchange of views. Table 4 provides an illustration of some of the items arising for each theme.

Insert table 4 here

Phase 3. Based on the item pool generated in phase 2, two large full-day externally facilitated workshops identified the 20 most suitable items for possible inclusion in the questionnaire under development. These 20 items were then discussed at a user and carer project advisory group meeting, which confirmed that they were appropriate and relevant for inclusion in the questionnaire, subject to some minor amendments.

Table 5 depicts the final CMHT effectiveness scale following Stage 1. In order to reduce the probability of acquiescent bias (Hinz et al., 2007), twelve items were positively worded and eight negatively worded. Dimensions had differing numbers of items attached to them, thus weighting them differently in a way that reflected the relative importance attached to each dimension by the Phase 3 workshop participants. Items were also randomly presented in the questionnaire rather than being grouped by dimension.

Insert table 5 here

\section{Stage 2: Quantitative findings}


Response rates. In total, 2233 questionnaires were dispatched and 1500 responses were returned from staff contributing to 135 CMHTs from 11 Trusts in different localities across England (120 teams completed the online survey, and 15 completed the postal survey). The overall response rate was $67.2 \%$, and Trust level response rates ranged between $50.4 \%$ and $88.8 \%$. The number of responses per Trust ranged between 42 respondents (representing 6 teams), to 236 respondents (representing 19 teams). The response rate for teams using postal methods was significantly lower $(34.0 \%)$ than those completing the survey online $(71.8 \%)$ (chi-square $=154.6,1$ d.f., $p<0.001)$. See table 6 for a breakdown of response rates by team type.

Insert table 6 here

Demographic profile. Of the 1500 participants, $72.3 \%$ were female. About $7.0 \%$ were $<30$ years of age, $20.9 \%$ between 30 and $39,37.6 \%$ between 40 and $49,29.7 \%$ between 50 and 59 , and $4.8 \% 60$ or older. A total of $82.3 \%$ were White British. These characteristics were congruent with the national profile of community-based staff in mental health trusts according to the 2009 NHS National Staff Survey (Care Quality Commission, 2010), where $73.8 \%$ were female, $80.4 \%$ White British and the age profile was also very similar.

Occupational group profile. The most common occupational group was community psychiatric nurses (CPNs, 32.6\% of sample). Administrative/clerical staff (11.4\%) and social workers $(11.1 \%)$ came next, followed by psychiatrists $(7.9 \%)$, occupational therapists $(6.5 \%)$, support time recovery workers (STRs, 5.5\%), clinical psychologists and other nurses (each $5.1 \%$ ), with $1.2 \%$ describing themselves as other medical practitioners, and $13.6 \%$ as other occupational groups (which were largely joint roles or slight variations on the above labels). These percentages were broadly similar to those for community based mental health staff in 
the 2009 NHS National Staff Survey (Care Quality Commission, 2010), with some slight discrepancies because of the specific make-up of these teams. For example, social workers are poorly represented in the NHS National Staff Survey as they are not necessarily employed by NHS Trusts.

Team participation profile. The majority (73.9\%) of the sample worked in only one CMHT, but $17 \%$ worked in two teams, $4.8 \%$ in three, $2.6 \%$ in four, $0.6 \%$ in five and $1 \%$ in more than five teams. Psychiatrists and clinical psychologists were most likely to work across more than one team. Mean time spent in post was 7 years, with a mean team tenure of 5 years.

Exploratory factor analysis. The CMHT effectiveness scale (20 items) yielded a potential three factor solution. The first factor accounted for $39.4 \%$ of the total variance; the second a further $6.1 \%$, the third $5.3 \%$, with subsequent factors all explaining $\leq 4.6 \%$ (eigenvalue $<1$ ). This suggested that a single factor might adequately cover the effectiveness domain, although a second factor may prove useful too, and possibly even a third (Table 7).

Insert table 7 here

The three factor solution added nothing useful to the two factor solution, as the third factor had no high factor loadings, and the first two factors were almost identical to the two factor solution. The two factor solution appeared to include the negatively worded items into a separate factor (a method-related factor), rather than discriminate content in any way. Thus, this offered no advantage over the one factor solution. Within the one factor solution, all items had a loading of $>0.4$ apart from item 9 ('Service users rarely receive care from the 
same members of my team'). This was possibly due to differing perceptions of the item meaning, which could have been perceived by some respondents as a positively worded statement, and by others as a negative one. Hence, four different solutions were tested by CFA: single factor solution containing all items; single factor solution containing all items except item 9; two-factor solution based on the EFA results; and, seven-factor solution based on the original seven domains from the Stage 1 workshops.

Confirmatory factor analysis. Table 8 depicts the fit indices for the four competing models.

Insert table 8 here

There was little to choose between the models on the basis of fit. The two-factor model appeared marginally better than the others, but this would not be so theoretically meaningful, as the factors could only really be distinguished as "effectiveness" and "ineffectiveness", rather than being based on separate domains of effectiveness. The 7-factor solution appeared to fit reasonably, but there were inadmissibly large correlations between the factors and also a complete lack of discriminant validity (as well as parsimony) in the model. Hence, we chose between the two single factor solutions: whilst dropping item 9 improved some fit indices, it worsened others, and all 20 items were therefore retained to function as a single effectiveness construct. The reliability of the overall scale was excellent, with Cronbach's alpha $=0.91$ (which was the same even if item 9 was excluded). Due to the task-specific nature of some of the scale items, we repeated the analysis for each of the four team types with sufficient responses ( $\leq 200$ individuals) to enable such analysis. In each instance, a single factor solution seemed to be better than a multiple-factor solution, with a 
two-factor model representing a split between positive and negative items. The reliability of this single factor was $0.89-0.92$ in each instance.

Overall, the results from Stage 2 suggested that the seven domains that emerged in Stage 1 are better thought of as components of the 'effectiveness' dimension, rather than separate dimensions in their own right. Further, the inter-rater reliability [ICC(2)] of the CMHT effectiveness scale was 0.57 (considered fair to good), and the inter-rater agreement mean $\left[r_{W G(J)}\right]$ was 0.99 , suggesting that the scale is suitable for use at the group level of analysis.

\section{Discussion}

Although the importance of team-based working in the delivery of healthcare is widely acknowledged (Manser, 2009), MPTW poses particular challenges for CMHTs and a reliable measure of CMHT effectiveness in the current context and service configuration of mental healthcare is lacking. Given our overall aim, the major contribution of this paper is the development of a new contextually specific measure of effective MPTW in community mental healthcare.

In relation to the first objective of the study, we applied the ProMES methodology to the development of a context specific scale, the CMHT effectiveness scale that captures multiple stakeholder perspectives, thus enhancing content and face validity. The new measure has two significant advantages over similar existing tools (e.g., Rees et al., 2001; Richards \& Rees, 1998). Firstly, its development took place in the era of specialist CMHTs, and it is therefore deemed to be valid across not only traditional generic CMHTs, but also Early Intervention, Assertive Outreach, Substance Misuse, Rehabilitation and Recovery, and Crisis Resolution/Home Treatment teams. This makes it applicable to a wide range of teams providing community mental healthcare, rendering it a highly relevant and powerful tool for 
NHS Trusts. In comparing the dimensions of the new CMHT effectiveness scale with the previously published CMHTEQ (Richards \& Rees, 1998), which focused only on generic CMHTs, a number of aspects appear to remain important for effective team working in this context. These include the involvement of carers in the team, establishing trust and respect between professional groups, and building therapeutic relationships with service users to foster recovery and well-being. However, the CMHT effectiveness scale also captures new and novel dimensions which are likely to reflect the range of team types examined as well as the changing context of community mental healthcare since the CMHTEQ's publication over fifteen years ago. These include the importance of providing continuity in the delivery of care; the need for creative and flexible problem solving that puts the service user at the heart of the team, and significance of effective inter-team working in order to ensure the smooth referral and management of service users between different teams.

The second major advantage was the significant involvement of service users and carers in the development process. The ProMES methodology (Pritchard, 1990) was successful for the current research because it enabled the positive integration of major (and often conflicting) stakeholder perspectives into the development of a comprehensive measure. This process contributed considerably to the scale's psychometric robustness, face validity and its suitability for the unique function of CMHTs in the current healthcare context in England. The ProMES methodology ensured that the dimensions included in the final scale captured the unique perspectives of these groups and particularly what they considered the most important outcomes of the care process. The finalised measure incorporates three dimensions which are highly pertinent to service users and carers - improved service user well-being, therapeutic relationships with service users, and engagement with carers. The new measure should therefore resonate not only with service providers, but also service users 
and carers in CMHTs. This resonance was evident in the reaction of study participants when reviewing the final version of the scale.

An additional significant contribution of this paper is the method used for scale development. Recognising that stakeholder involvement was crucial to the development of a reliable and valid CMHT effectiveness measure, we adapted a well-validated development approach, ProMES, to develop a new procedure that was a hybrid of this and other previous approaches. The various steps outlined in our methodology demonstrate that it is possible to use an adapted ProMES methodology for the purpose of developing measures of effectiveness for health and social care teams. More specifically, we conducted a series of workshops in three phases using a large number of diverse stakeholder groups. The methodology enabled these groups firstly to identify the key dimensions of CMHT effectiveness (Phase 1), before describing what these dimensions look like in practice (Phase 2), and finally refining and weighting items which represented them (Phase 3). The main stages of ProMES that we omitted from our approach were defining contingencies, defining the feedback system, giving and responding to feedback, and monitoring over time (Pritchard, 1990) - steps which should lead to performance improvements if team members bought into the CMHT effectiveness dimensions. Although the participating teams in Stage 2 did receive feedback in the form of a report (benchmarking all teams against one another), resource limitations did not allow for more a detailed follow up with the teams. Nevertheless we believe this would have been helpful and we have certainly demonstrated that our adapted ProMES approach enables the development of effectiveness tools in mental health care, as well as in other health and social care contexts.

Regarding our second objective, we assessed the psychometric properties of the newly arising CMHT effectiveness scale using quantitative data from 135 teams based in 11 Mental Health Trusts in England. Results demonstrated that a 20 item measure capturing a single 
factor of CMHT effectiveness demonstrated good structural validity based on both EFA and CFA. Overall, the new measure provides service providers, users and carers with an important and relatively lean conceptual framework in the form of seven dimensions or themes which capture what effectiveness constitutes in the context of community mental health team performance.

This CMHT effectiveness scale can be utilised in several ways. First and foremost, it can be used locally by CMHTs to self-assess their own effectiveness and performance. Using repeated measures over time, teams can monitor and evaluate their progress, identify discrepancies in their processes, and bring about positive change from within the team. The measure could also be employed by service users and carers to review the services they receive from teams. At the organisation level, the measure will be of interest to audit bodies such as the Care Quality Commission to inform the criteria they use to evaluate the adequacy of multi-professional team working in community mental healthcare; by commissioners of services to monitor the effectiveness of the CMHTs they commission; and by both policy makers and the general public to understand what is important in assessing the delivery of community mental health care by multi-professional teams. By widely employing the measure across NHS Trusts, it would be possible to generate 'norms' or national 'benchmarks' of what adequate team working in CMHTs looks like, against which teams could monitor and compare their own functioning. The seven dimensions identified in the measure therefore provide important guidance to a range of interested stakeholders at different levels.

This study has limitations. Firstly, given that this CMHT measure was developed under the new era of specialist mental health teams in England, it is not specific enough to indicate particular areas of effectiveness that would only be applicable to one type of team, (e.g., Early Intervention for Psychosis). A second limitation concerns the representativeness 
of the sample. As team members (Stage 1) and teams (Stage 2) were drawn from only 11 selfselecting mental health trusts across England, it could be argued that Trusts that chose to participate in the research were better at developing well-structured CMHTs and so were more willing to take part. Such self-selection may have influenced the nature and content of the themes of CMHT effectiveness that emerged via ProMES in Stage 1, as well as the way in which participants responded to the questionnaire in Stage 2. Nevertheless, the new measure demonstrated good psychometric properties and the sample size, both at the team and individual level, was relatively large in comparison to other scale development studies. Further, establishing predictive validity is needed to ensure that the teamwork outcomes identified by stakeholders map onto objective teamwork outcomes (e.g., team errors and incidents, team member absenteeism, or service user readmission rates).

Future research would also benefit from exploring the antecedents of CMHT effectiveness in a broader Input-Process-Output model of team performance. The new measure could be used to compare different specialist types of CMHTs, to examine which team types score highest on the various effectiveness dimensions and why. Indeed, using an existing team effectiveness framework (the Aston Team Performance Inventory; West et al., 2005), later stages of this research project went on to examine which team inputs (e.g. task design, composition, organisational support) and team processes (e.g. leadership, reflexivity, participation) were most important for developing CMHT effectiveness in CMHTs, the findings of which are currently being written up for future publication. Future research might also examine possible item redundancy as a way of determining if the 20 item measure could be shortened at all.

In summary, the reliable and statistically confirmed scale of CMHT effectiveness presented in this paper will be of significant value to both service providers and commissioners as they work together to identify and finance appropriate services in years to 
come. Further, the new measure provides a much-needed and unique way of generating quantifiable data about the activities, processes and effectiveness of CMHTs which will serve to guide decision makers as they plan resources for mental health services nationally and internationally. 


\section{References}

Braun, V., \& Clarke, V. (2006). Using thematic analysis in psychology. Qualitative Research in Psychology, 3(2), 77-101.

Brown, B., Crawford, P., \& Darongkamas, J. (2000). Blurred roles and permeable boudaries: the experience of multidisciplinary working in community mental health. Health and Social Care in the Community, 8(6), 425-435.

Care Quality Commission. (2010). Staff survey 2009. Retrieved September 24, 2009, from http://webarchive.nationalarchives.gov.uk/20110718105843/http://www.cqc.org.uk/abou tcqc/howwedoit/engagingwithproviders/nhsstaffsurveys/previoussurveys.cfm

Conway, J. M., \& Huffcutt, A. I. (2003). A review and evaluation of exploratory factor analysis practices in organizational research. Organizational Research Methods, 6, 147168.

Department of Health. (1999). National service framework for mental health: modern standards and service models. London: Department of Health.

Department of Health. (2001). The mental health policy implementation guide. London: Department of Health.

Dickinson, H. E., Peck, E., \& Davidson, D. C. (2007). Opportunity seized or missed? A case study of leadership and organizational change in the creation of a Care Trust. Journal of Interprofessional Care, 21, 503-513.

El Ansari, W. (2003). Educational Partnerships for Health: Do Stakeholders Perceive Similar Outcomes? Journal of Public Health Management and Practice, 9, 136-156. 
El Ansari, W. (2011). When meanings blur, do differences matter? Initiatives for improving the quality and integration of care: conceptual matrix or measurement maze? Journal of Integrated Care, 19(3), 5-21.

Glaser, B. G., \& Strauss, A. L. (1967). The Discovery of Grounded Theory: Strategies for Qualitative Research. Chicago: Aldine Publishing Company.

Hinkin, T. (1995). A review of scale development practices in the study of organizations. Journal of Management, 21(5), 967-988.

Hinz, A., Michalski, D., Schwarz, R., \& Herzberg, P. Y. (2007). The acquiescence effect in responding to a questionnaire. GMS Psycho-Social-Medicine, 4, 1-9.

Hu, L., \& Bentler, P. M. (1998). Fit indices in covariance structure modeling: Sensitivity to underparameterization model misspecification. Psychological Methods, 3, 424-453.

IBM (2010). SPSS Statistics for Windows, Version 19.0. Armonk, NY: IBM Corp.

Jansen, L., \& Glasby, J. (2008). Collaborative and interdisciplinary health care teams: ready or not? Journal of Professional Nursing, 24(4), 218-27.

Lester, H., \& Glasby, J. (2012). Mental Health Policy and Practice (2nd ed.). Hampshire: Palgrave.

Manser, T. (2009). Teamwork and patient safety in dynamic domains of healthcare: a review of the literature. Acta anaesthesiologica Scandinavica, 53(2), 143-51.

Nembhard, I. M., \& Edmondson, A. C. (2006). Making it safe: the effects of leader inclusiveness and professional status on psychological safety and improvement efforts in health care teams. Journal of Organizational Behavior, 27(7), 941-966. 
Onyett, S. (2003). Teamworking in Mental Health. Hampshire: Palgrave.

Pritchard, R.D. (1990). Measuring and improving organizational productivity: A practical guide. New York: Praeg.

Pritchard, Robert D., Harrell, M. M., DiazGranados, D., \& Guzman, M. J. (2008). The productivity measurement and enhancement system: A meta-analysis. Journal of Applied Psychology, 93(3), 540-567.

Rees, A., Stride, C., Shapiro, D., Richards, A., \& Borrill, C. (2001). Psychometric properties of the Community Mental Health Team effectiveness questionnaire (CMHTEQ). Journal of Mental Health, 10(2), 213-222.

Rees, G., Huby, G., McDade, L., \& McKechnie, L. (2004). Joint working in community mental health teams: implementation of an integrated care pathway. Health and Social Care in the Community, 12(6), 527-536.

Richards, A., \& Rees, A. (1998). Developing criteria to measure the effectiveness of community mental health teams. Mental Health Care, 2(1), 14-17.

West, M. A., Alimo-Metcalfe, B., Dawson, J. F., El Ansari, W., Glasby, J., \& Hardy, G. (2012). Effectiveness of Multi-Professional Team Working (MPTW) in Mental Health Care. Final Report.

West, M. A., Markiewicz, L., \& Dawson, J. F. (2005). Aston Team Performance Inventory: Management Set. London: ASE. 
Table 1. CMHT typology

\begin{tabular}{ll}
\hline \multicolumn{1}{c}{ Team Type } & \multicolumn{1}{c}{ Team Function } \\
\hline $\begin{array}{l}\text { Community Mental Health (or } \\
\text { Primary Care Liaison) teams }\end{array}$ & $\begin{array}{l}\text { Serve needs of all mental health service users within } \\
\text { their localities }\end{array}$ \\
\hline Assertive Outreach teams (AOTs) & $\begin{array}{l}\text { Work with 'hard to engage' people living in the } \\
\text { community }\end{array}$ \\
\hline Crisis Resolution and Home & Work as an alternative to hospital admission for \\
Treatment teams (CRHTs) & individuals experiencing acute crises in their mental \\
& health \\
\hline Early Intervention (EI) teams & Work with young adults (14 - 35 years) who are \\
& $\begin{array}{l}\text { either at risk of or currently experiencing a first } \\
\text { episode of psychosis }\end{array}$ \\
\hline Older adults (OA) teams & $\begin{array}{l}\text { Work with older people ( } \geq 65 \text { years), many of whom } \\
\text { suffer from depression or dementia and may have } \\
\text { comorbid physical disabilities and impairments }\end{array}$ \\
\hline Substance Misuse (SM) teams & $\begin{array}{l}\text { Provide specialist interventions for mental health } \\
\text { service users with drug and alcohol misuse }\end{array}$ \\
\hline Rehabilitation and Recovery (RR) & $\begin{array}{l}\text { Provide care co-ordination for service users being } \\
\text { reams }\end{array}$ \\
& $\begin{array}{l}\text { resettled from inpatient rehabilitation units into less } \\
\text { dependent settings }\end{array}$ \\
\hline
\end{tabular}

Source: West et al. (2012) 
Table 2. Qualitative perspectives on CMHT effectiveness: Three phases of inquiry by stakeholder and location

\begin{tabular}{|c|c|c|c|c|c|c|c|}
\hline Phase & Overall Aim & Workshop design & Location & $\begin{array}{l}\text { Service } \\
\text { providers }\end{array}$ & $\begin{array}{l}\text { Service } \\
\text { users }\end{array}$ & Carers & Details and examples \\
\hline 1 & $\begin{array}{l}\text { Researchers listen } \\
\text { to participants' } \\
\text { accounts of } \\
\text { working in } \\
\text { CMHTs }\end{array}$ & $\begin{array}{l}\text { Two large full-day } \\
\text { workshops facilitated } \\
\text { by an external } \\
\text { facilitator experienced } \\
\text { in working with health } \\
\text { care professionals. } \\
\text { Workshops supported } \\
\text { by research team. }\end{array}$ & $\begin{array}{l}\text { Birmingham } \\
\text { London }\end{array}$ & $\begin{array}{l}20 \\
20\end{array}$ & $\begin{array}{l}7 \\
8\end{array}$ & $\begin{array}{l}5 \\
5\end{array}$ & $\begin{array}{l}\text { Each workshop had five sessions: } \\
\text { 'What works for me?' } \\
\text { 'What we do to make a difference' } \\
\text { 'How do teams work to support good } \\
\text { outcomes for service users?' } \\
\text { 'What are the challenges to effective team } \\
\text { working?' }\end{array}$ \\
\hline 2 & $\begin{array}{l}\text { Focus on three or } \\
\text { four of the seven } \\
\text { themes derived } \\
\text { from Phase } 1 \\
\text { (subject to time } \\
\text { available and size } \\
\text { of group) }\end{array}$ & $\begin{array}{l}\text { Six workshops, } \\
\text { facilitated by } \\
\text { members of the } \\
\text { research team. } \\
\text { Each workshop began } \\
\text { with a summary and } \\
\text { discussion of Phase } 1 \\
\text { outcomes, followed } \\
\text { by two sessions. }\end{array}$ & $\begin{array}{l}\text { Birmingham } \\
\text { London } \\
\text { Nottingham } \\
\text { Birmingham } \\
\text { Birmingham } \\
\text { Gloucester }\end{array}$ & $\begin{array}{l}6 \\
6 \\
10 \\
- \\
- \\
6\end{array}$ & $\begin{array}{l}- \\
- \\
- \\
8 \\
-\end{array}$ & $\begin{array}{l}- \\
- \\
- \\
- \\
9 \\
-\end{array}$ & $\begin{array}{l}\text { Session 1: One of the seven CMHT themes } \\
\text { introduced, participants provided with } \\
\text { quotes from Phase 1, then asked: } \\
\text { 'If (theme name) was happening, how } \\
\text { would we know?' } \\
\text { 'If (theme name) was not happening, what } \\
\text { would we see?' } \\
\text { Session 2: Small groups ( } 2-5 \text { participants) } \\
\text { to repeat session } 1 \text { exercise using a different } \\
\text { theme. }\end{array}$ \\
\hline 3 & $\begin{array}{l}\text { Based on items } \\
\text { from phase } 2, \\
\text { phase } 3 \text { refined a } \\
\text { final list of items } \\
\text { for the CMHT } \\
\text { effectiveness scale }\end{array}$ & $\begin{array}{l}\text { Two large full-day } \\
\text { workshops externally } \\
\text { facilitated by the same } \\
\text { Phase } 1 \text { facilitator. } \\
\text { Workshops supported } \\
\text { by research team. }\end{array}$ & $\begin{array}{l}\text { Birmingham } \\
\text { London }\end{array}$ & $\begin{array}{l}10 \\
20\end{array}$ & $\begin{array}{l}7 \\
3\end{array}$ & & $\begin{array}{l}\text { Participants worked in small groups, } \\
\text { examining wording of items in one of the } \\
\text { themes from Table } 3 \text {. Each group was } \\
\text { required to discuss evaluate and, if } \\
\text { necessary, discard, refine or reword the } \\
\text { proposed questionnaire items. Small groups } \\
\text { then rotated to work on a different theme. }\end{array}$ \\
\hline
\end{tabular}


Table 3. CMHT effectiveness: Example stakeholder comments by theme (Phase 1)

\begin{tabular}{l|l}
\hline \multicolumn{1}{c|}{ Theme } & \multicolumn{1}{c}{ Example stakeholder comments } \\
\hline $\begin{array}{l}\text { Improved service user } \\
\text { well-being }\end{array}$ & $\begin{array}{l}\text { Putting the service user at the centre of the team. } \\
\text { Working with people during and beyond recovery to } \\
\text { improve longer term outcomes and opportunities. } \\
\text { Team makes a positive impact on someone's quality of life. }\end{array}$ \\
\hline $\begin{array}{l}\text { Therapeutic relationships } \\
\text { with service users }\end{array}$ & $\begin{array}{l}\text { Providing a safe environment - compassion. } \\
\text { Feel the pain with me; share my journey. } \\
\text { Accept me, take me seriously and care about what happens. }\end{array}$ \\
\hline $\begin{array}{l}\text { Provision of continuous } \\
\text { care }\end{array}$ & $\begin{array}{l}\text { Having the same people visit you. } \\
\text { Consistent medical advice - no conflicting messages. }\end{array}$ \\
\hline $\begin{array}{l}\text { Effective inter-team } \\
\text { working }\end{array}$ & $\begin{array}{l}\text { Cooperative interdependence between teams. } \\
\text { Effective inter-team working over transition periods. }\end{array}$ \\
\hline Engagement with carers & $\begin{array}{l}\text { Transparency and openness with carers (confidentiality). } \\
\text { Carer involvement in decision-making. }\end{array}$ \\
\hline Creative problem solving & $\begin{array}{l}\text { Positive risk taking - creative solutions. } \\
\text { Setting challenging but realistic goals. }\end{array}$ \\
\hline $\begin{array}{l}\text { Respect between } \\
\text { professionals }\end{array}$ & $\begin{array}{l}\text { Shared culture/philosophy, trust, and shared responsibility. } \\
\text { Respect and understanding for different professions. } \\
\text { Having the right skills, knowledge and resources to hand. }\end{array}$
\end{tabular}


Table 4. CMHT effectiveness: Key outcomes for each theme (Phase 2)

\author{
If 'improved service user well-being' is happening, what would we see? \\ Improved self-esteem and quality of life of service user (social functioning, relationships) \\ Service users empowered and supported in making choices to achieve their full potential \\ Observant teams that listen to service users, and help them to rebuild routines and plans \\ Regular meetings involving service users to discuss future support - increased efficiency \\ If 'therapeutic relationships with service users' is happening, what would we see? \\ Time dedicated to listening to service users \\ Treating people holistically, rather than on basis of diagnosis alone \\ Relationships between service providers and service users that are based on support, trust, \\ empathy and truth \\ Increased speed of recovery - clear expectations fewer complaints
}

If 'provision of continuous care' is happening, what would we see?

Continuity in care planning, treatment, goal setting and goal achieving at each stage

Seamless and creative transition through service with effective clear communication

Gradual agreed preparation of service user for discharge

Awareness of and adaptability to service user needs to promote independence and recovery

of service user

If 'effective inter-team working' is happening, what would we see?

Collaborative working with other teams and services - administrative efficiency

Clarity of roles: everyone is aware of who is accountable/taking ownership

Demonstrating good practice leading to reduced risks; Improved well-being of team workers

Greater flexibility in roles where people are willing and motivated to go the extra mile

If 'engagement with carers' is happening, what would we see?

Education about carers' role; Carers being treated as part of the team; Happy/satisfied carers

Service user updates - frequent feedback and open communication

Reciprocating carers - if providers know where carers are, carers know where providers are

Healthy caring - allowing service users freedom to make choices

If 'creative problem solving' is happening, what would we see?

Learning to see the way through a problem and think outside of the box

Seeing service user as a whole person who's care plan is tailored to their needs

Recognition/acceptance that not everything is going to work, but there is a willingness to try

Reduced/flatter hierarchy which facilitates idea generation and sharing

If 'respect between professionals' is happening, what would we see?

Mutual respect within hierarchies - healthy interdisciplinary conflict within an open culture

Culture of understanding and willingness to learn from/understand each other

'Seamless' services: collaborative, transparent, joint working between teams and services

Communication, a common understanding/language within the team - shared risk 
Table 5. CMHT effectiveness: Final scale items (Phase 3) 
Table 6. Questionnaire responses by type of team (Stage 2)

\begin{tabular}{lccc}
\hline & $\begin{array}{c}\text { Number } \\
\text { of teams }\end{array}$ & $\begin{array}{c}\text { Number of } \\
\text { respondents }\end{array}$ & $\begin{array}{c}\text { Response rate } \\
(\%)\end{array}$ \\
\hline Type of team & 32 & 366 & 63.2 \\
\hline Generic CMHT* & 18 & 163 & 69.7 \\
Assertive Outreach & 22 & 204 & 64.4 \\
Early Intervention & 11 & 138 & 64.5 \\
Crisis Resolution/Home Treatment & 26 & 335 & 74.8 \\
Rehabilitation \& Recovery (R\&R) & 20 & 230 & 66.3 \\
Older adults CMHT & 3 & 30 & 55.6 \\
Substance Misuse & 1 & 15 & 86.7 \\
Intensive Support & 1 & 7 & 85.7 \\
Liaison Psychiatry & 1 & 18 & 83.3 \\
Assertive Outreach/R\&R & R R & \multicolumn{2}{l}{}
\end{tabular}


Table 7. Factor loadings based on EFA of the CMHT effectiveness scale

\begin{tabular}{|c|c|c|c|c|c|c|}
\hline \multirow{2}{*}{$\begin{array}{l}\text { Item } \\
\text { Improved service user well-bein }\end{array}$} & \multirow[t]{2}{*}{ One factor } & \multicolumn{2}{|c|}{ Two factors } & \multicolumn{3}{|c|}{ Three factors } \\
\hline & & & & & & \\
\hline 1. Improved sense of well-being & 0.68 & 0.70 & 0.01 & 0.69 & -0.02 & -0.18 \\
\hline 2. Building positive aspects & 0.73 & $\mathbf{0 . 8 3}$ & 0.11 & 0.81 & 0.07 & -0.05 \\
\hline 3. No involvement in care plans & -0.55 & 0.26 & 0.34 & 0.26 & 0.36 & 0.09 \\
\hline 4. Next step on path to recovery & 0.66 & 0.72 & 0.05 & 0.69 & 0.02 & 0.00 \\
\hline 5. Servicer user views & 0.77 & 0.76 & -0.02 & 0.75 & -0.03 & 0.08 \\
\hline \multicolumn{7}{|c|}{ Therapeutic relationships with service users } \\
\hline 6. Poorly defined boundaries & -0.41 & 0.02 & $\mathbf{0 . 5 0}$ & 0.03 & 0.52 & 0.10 \\
\hline 7. Open relationships & 0.59 & 0.62 & 0.03 & 0.61 & 0.01 & 0.06 \\
\hline 8. Listen to service users & 0.78 & $\mathbf{0 . 8 3}$ & 0.03 & 0.81 & 0.01 & 0.06 \\
\hline \multicolumn{7}{|l|}{ Provision of continuous care } \\
\hline 9. Care from same rare & -0.33 & 0.09 & 0.28 & 0.08 & 0.31 & 0.13 \\
\hline 10. Contacts other teams & 0.58 & 0.46 & -0.15 & 0.45 & -0.18 & -0.20 \\
\hline 11. Flexible workload & 0.62 & 0.49 & -0.16 & 0.49 & -0.14 & 0.23 \\
\hline \multicolumn{7}{|l|}{ Effective inter-team working } \\
\hline 12. Unclear referral processes & -0.41 & 0.05 & 0.54 & 0.03 & 0.52 & -0.02 \\
\hline 13. Ineffective communication & -0.60 & 0.16 & 0.52 & 0.16 & 0.52 & 0.04 \\
\hline Engagement with carers & - & & & & & \\
\hline 14. Carers not important & -0.51 & 0.31 & 0.24 & 0.30 & 0.27 & 0.14 \\
\hline 15. Offers information to carers & 0.65 & 0.65 & -0.01 & 0.64 & -0.04 & -0.13 \\
\hline Creative problem solving & 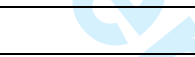 & & & & & \\
\hline 16. One size does not fit all & 0.72 & 0.70 & -0.04 & 0.68 & -0.05 & 0.03 \\
\hline 17. New ways of providing care & 0.64 & 0.55 & -0.11 & 0.57 & -0.07 & 0.35 \\
\hline 18. No sharing of good practice & -0.50 & 0.01 & 0.61 & 0.00 & 0.59 & -0.13 \\
\hline \multicolumn{7}{|l|}{ Respect between professionals } \\
\hline 19. Lack of mutual respect & -0.46 & 0.04 & 0.49 & 0.03 & 0.49 & -0.20 \\
\hline 20. Willingness to learn & 0.66 & 0.43 & -0.27 & 0.42 & -0.26 & 0.27 \\
\hline
\end{tabular}

Note: EFA was conducted using principal axis factoring and a direct oblimin (oblique) rotation; actual wording of items has been abbreviated in table; negatively worded items in italics; factor loadings of magnitude $\geq 0.4$ are bolded as they represent the items that most contribute towards respective factors. 
Table 8. Confirmatory factor analysis of CMHT effectiveness scale

\begin{tabular}{lccccc}
\hline Model & Chi-square (df) & SRMR & CFI & TLI & RMSEA \\
\hline 1 factor $(20$ items) & $687.4(170)$ & 0.044 & 0.904 & 0.893 & 0.068 \\
1 factor $(19$ items) & $634.6(152)$ & 0.043 & 0.909 & 0.897 & 0.069 \\
2 factors & $456.6(118)$ & 0.037 & 0.930 & 0.919 & 0.066 \\
7 factors & $548.5(149)$ & 0.040 & 0.926 & 0.906 & 0.064 \\
\hline
\end{tabular}

Note: SRMR: standardised root mean residual (ideally $<0.1)$; CFI: comparative fit index (ideally $>0.90$ ); TLI: Tucker-Lewis index (ideally $>0.90$ ); RMSEA: root mean square error of approximation (ideally $<0.08$ ) 